\title{
DATA-DRIVEN DESIGN CHALLENGES IN THE EARLY STAGES OF THE PRODUCT DEVELOPMENT PROCESS
}

\author{
Briard, Tristan (1); \\ Jean, Camille (1); \\ Aoussat, Améziane (1); \\ Véron, Philippe (1); \\ Le Cardinal, Julie (2); \\ Wartzack, Sandro (3) \\ 1: École nationale supérieure d'arts et métiers (ENSAM); \\ 2: CentraleSupélec (CS); \\ 3: Friedrich-Alexander-Universität Erlangen-Nürnberg
}

\begin{abstract}
With the rapid development of digital technologies, products connectivity is increasing as well as the data produced and collected. Forecasts on product development predict that this trend will keep on growing. In this context, new design solutions based on data are emerging. Those data-driven design approaches are common for identifying the customers' need when developing a new product. However, few studies cover data-driven design in the other early stages of product design. Thus, the research question addressed in this paper is: what are the challenges of data-driven design research in the early phases of the product development process? Through a literature review and a workshop proposed at the conference DESIGN 2020, this paper offers a first glimpse of future research leads. A list of 5 challenges for data-driven design in the early stages of product design is proposed and ranked from short term to long term.
\end{abstract}

Keywords: Data-driven design, Internet of Things, Early design phases, Design practice, Big data

\section{Contact:}

Briard, Tristan

École nationale supérieure d'arts et métiers (ENSAM)

LCPI - Laboratoire Innovation Conception Produit

France

tristan.briard@ensam.eu 


\section{INTRODUCTION}

Nowadays, with the rapid development of digital technologies, complex solutions are becoming more accessible. This trend has enabled the evolution of products by making them both smarter and more connected. Alongside, the collection and usage of data naturally followed this development. The Design Society report by Isaksson and Eckert (2020) forecasts the future of products and development processes in 2040. The products of the future will involve even greater connectivity between the user, the product and the manufacturer. Data is an essential mean of monitoring the behaviour of existing products, processes and users for optimization purpose. Its use is also predicted to keep on increasing in the future product development process. In this context, Data-Driven Design (DDD) approaches are emerging. DDD is often associated with the usage of data during the design process. However, there is a lack of unified definition of DDD (Zheng et al. 2020). Despite being acknowledged as an important tool of design for the upcoming years (Kim et al. 2017), DDD is limited and far from being mature yet in product design. A review of the existing literature about DDD by Bertoni (2020) helped grasp its current use in the product development process. Most of the research in the early stages concern the phase "identifying customers' needs" and rely on data mining. Companies don't have the tools and resources to effectively integrate DDD in their product development phases. They tend to emphasise on low effort and cost solutions, for example text mining on online reviews. Research in design science should showcase the potential of a structured and dedicated DDD approach. However, to this day, only a handful of research tries to integrate data upstream in the product development stages. In the face of this observation, the research question addressed in this paper is: what are the challenges of data-driven design research in the early phases of the product development process? The objective of this paper is to highlight research leads for future works. To answer this question, the following approach (Figure 1) was conducted. A literature review of DDD use in the early product development stages and the currently related challenges was carried out. Based on this preliminary study, a workshop was organised and held at DESIGN 2020 to provide an in-depth answer. Participants shared their views on the research question through the different themes addressed during the workshop. Identified DDD challenges during the literature review and the workshop were then synthesised in a proposition of a research agenda.

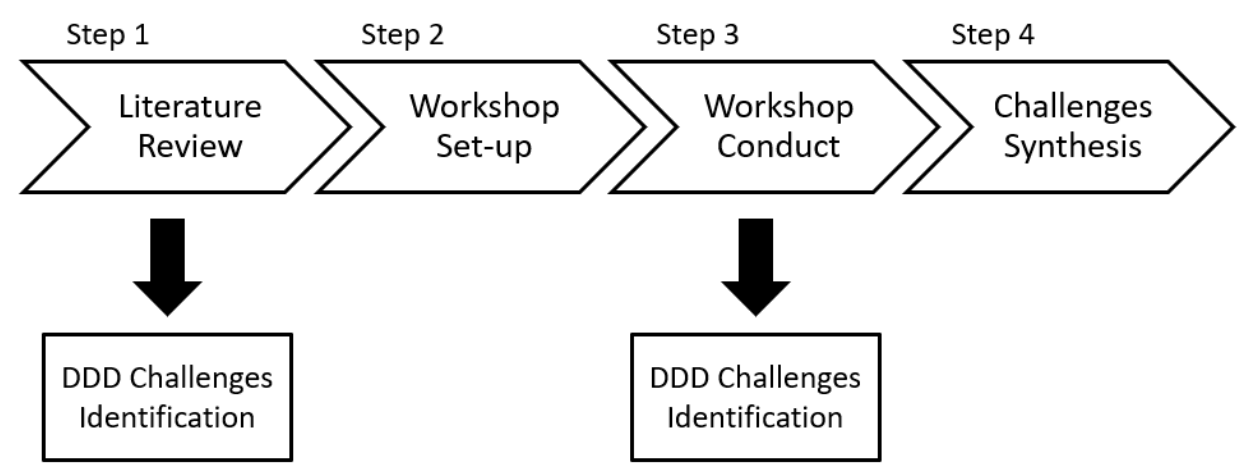

Figure 1. Research approach

In section 2, the literature review of DDD use and its challenges in early product design is proposed. The workshop and its outcomes are then presented in section 3. Finally, section 4 discuss and draw a picture of DDD challenges in the early stages of design.

\section{LITERATURE REVIEW}

The rapid development of data has enabled numerous new opportunities and deeply changed design habits. During the product development process, data can complement the expertise of the stakeholders in various ways. Thus, tools and methods integrating data have been proposed to assist designers and reduce development time. In this literature review, examples of DDD in product design are presented. The process chosen as reference is the systematic approach of product design by Pahl and Beitz (1996). As the scope of research is "DDD in the early stages of product design", only the first three phases "Clarification of the task", "Conceptual Design" and "Embodiment Design" are considered in this review. Other product design process could also have been used to organise this state-of-the-art, for example the user-centric approach of Design Thinking (Faste et al. 1993). 
However, when given the choice, the participants of the workshop had preferred to work with this systematic approach.

\subsection{Clarification of the task}

During the "Clarification of the task" phase, DDD is mostly used to identify the customers' needs through data mining (Bertoni 2020). For example, Bae and Kim (2011) used data mining on surveys to identify and highlight key functional attributes that influence purchase of digital cameras. New products' requirements could then be suggested for the next product generation. In the same way, Lin et al. (2016) and Chien et al. (2016) both proposed data mining on surveys to link the user experience with the aesthetic of a product. The identified preferences are also integrated into the design specifications to enhance customers' satisfaction. A similar but more advanced approach is proposed by Yang et al. (2019). User experiences are mined from large volume of customer online data and three main elements are extracted: the concerned product feature, the context of use and the associated sentiment. Designers could then highlight and emphasis on key features, re-think product issues but moreover discover complex user experience patterns through these data. Romelfanger and Kolich (2019) applied data mining on car customers' feedbacks for seat optimization. New ergonomic design prescriptions are proposed to maximize overall comfort and therefore product satisfaction.

\subsection{Conceptual design}

In the same manner as the previously presented works for identifying the customers' needs, Chiu and Lin (2018) used data mining on online reviews. Customers preferred design components are identified using Kansei engineering and incorporated in the design specifications. But moreover, a conceptual design automation system is then proposed to generate preliminary computer-aided design solutions integrating customers' preferred components. DDD also enables innovation methods enhancing creativity by generating large number of design alternatives (Kusiak 2009). Various data-based tools have been developed for supporting the designers in concept generation. Kwon et al. (2018) proposed a tool based on Wikipedia data. For a given product, it automatically identifies the key features and design possibilities. It then generates the associated morphological matrix. Chen et al. (2019) developed two creativity tools based on data: a semantic tool and a visual one. The semantic tool mines potential knowledge connections across various domains in order to suggest new innovative ideas. With the same intent, the visual tool randomly generates images which synthesize two selected concepts. Ranscombe et al. (2017) proposed a digital comparison tool highlighting the differentiations in product shapes. This tool helps designers for distinction in the styling process. From a more technical point of view, Wilberg et al. (2018) proposed a library of 245 Internet of Things use cases for companies struggling with the development of connected products. This catalogue aims to provide design analogies through relevant use cases implementing data.

\subsection{Embodiment design}

The new opportunity to gather and exploit large amount of real-world data from products is also a key feature of DDD. It enables the possibility to continuously improve the design of products and to better meet the users' needs (Chowdhery et al. 2020). Indeed, product information usage can provide relevant knowledges and valuable inputs to designers in the product development process (Klein et al. 2019). For example, Lützenberger et al. (2016) proposed a use case designing bearings for a washing machine. Product information usage data gathered by sensors are used in mathematical equations determining the most adapted bearings and their expected lifespan. It also enables a real time monitoring of the product's condition and preventive maintenance possibilities. Another use case by Vegte et al. (2019) addresses the design of connected fridges. Real-life data gathered by sensors are supporting virtual simulations of usages and in the end the redesign of the next products' generation. Shin et al. (2015) and Ma et al. (2017) proposed similar works based on field data. With the help of sensors and data analytics, the defective design parameters related to abnormal field data are identified. Data are then utilized for a redesign to improve the product. Regarding the prototyping phase, Gosh et al. (2017) proposed the use case of a shoe with embedded sensors to monitor the walking data. Those data were then successfully translated into empathic data and appeared to be more accurate in the representation of comfort than surveys' answers. Such empathic feedbacks drawn from data can be used to improve the product design as well. 


\subsection{Data-driven design challenges}

With the introduction of DDD in the early stages of the product development process, challenges have also arisen. From a holistic perspective, Labrinidis and Jagadish (2012) have listed some challenges related to the use of data. DDD is not a straightforward process. In the face of the staggering amount of data available, there is first a need to define filters. Such filters should discard the useless data while extracting the useful information. Then, the extracted raw data need to be processed in a structured form for analysis. Moreover, conclusions drawn out of data are not foolproof, indeed data must be clean, trustworthy. Possible errors must be avoided in their capture, transmission and structuring. At last, the data interpretation is subjective. Concerning the product innovation process, Bertoni (2018) identified some challenges to be addressed in DDD. The data interpretation issue is also discussed and more developed. Product development is a multidisciplinary process involving different stakeholders. Thus, their approaches on data interpretations can be biased. Likewise, the priority and relevance of the different data to collect can also be based on personal experience and belief. Another challenge highlighted is the lack of data available in the earliest design phases of a brand new product. Cantamessa et al (2020) considered design from a broad point of view and identified the challenges brought by digitalisation on the designers and the design process. Some challenges raised are relevant for this literature review. Regarding the designers, the challenge on data processing is further discussed. The "extensive volumes, format and sources of data" as well as the "interoperability between systems" need to be mastered. Moreover, the growing availability of data will require designers to develop new data skills or the integration of data experts in the design process. Concerning the design process, the choice of the most appropriate data analytics tools and technics appeared as a challenge. Furthermore, the automation of certain parts of the design process through artificial intelligence and machine learning was also mentioned for future research. Bstieler et al. (2018) organised a workshop to develop and discuss promising research questions on "hot topics" including Big Data Analytics and Innovation. Several challenges proposed are suitable for this paper's study. Indeed, during the design process, most companies tend to use only descriptive data analysis. The need to better integrate predictive and prescriptive techniques was then highlighted as they represents an insightful set of tools. The need to integrate and collaborate with data scientist and IT experts was also discussed. Finally, Gorkovenko et al. (2020) also explored the future of Data-Driven Product Design through a few workshops. A lack of supports within product design to process and make sense out of data was identified. Thus, the development of design methods integrating data was found to be a challenge. In addition, the need for ethical design practices that respect user privacy was identified. This paper aims to further explore DDD challenges in early product design and to rank them according to their importance.

\section{WORKSHOP AT DESIGN 2020}

In order to complete the review of the literature and have an in-depth perspective, a workshop at the conference DESIGN 2020 was organised. The aim of this workshop was first of all to propose an interactive environment for the participants to learn from each other. The workshop addressed the research question: what are the challenges of data-driven design research in the early phases of the product development process? The objectives were first to understand the current opportunities of DDD within the product development process, then to explore the future possibilities and challenges. This workshop was held online by the Design Society Special Interest Group: Decision Making and was conducted in three parts (Figure 2).

\begin{tabular}{|c|c|c|c|c|c|c|}
\hline Context & \multicolumn{3}{|c|}{ Knowledge Sharing } & \multicolumn{3}{|c|}{ Speculating } \\
\hline $\begin{array}{l}\text { Presentation: } \\
\text { Challenges and } \\
\text { opportunities of } \\
\text { DDD in early } \\
\text { product } \\
\text { development }\end{array}$ & $\begin{array}{l}\text { Q1: What types } \\
\text { of data have you } \\
\text { encountered in } \\
\text { your works? }\end{array}$ & $\begin{array}{l}\text { Q2: What data } \\
\text { processing } \\
\text { methods have } \\
\text { you encountered } \\
\text { in your works? }\end{array}$ & $\begin{array}{l}\text { Q3: What data } \\
\text { visualisation } \\
\text { methods have } \\
\text { you encountered } \\
\text { in your works? }\end{array}$ & $\begin{array}{l}\text { Q4: What kind of } \\
\text { data would you } \\
\text { "dream" of } \\
\text { having access } \\
\text { to? }\end{array}$ & $\begin{array}{l}\text { Q5: What are the } \\
\text { next challenges } \\
\text { for DDD in the } \\
\text { coming years? }\end{array}$ & $\begin{array}{l}\text { Q6: Can you } \\
\text { rank the } \\
\text { identified } \\
\text { challenges from } \\
\text { short to long } \\
\text { term? }\end{array}$ \\
\hline
\end{tabular}

Figure 2. Workshop flow and structure 
In the first part, the workshop theme and objectives were highlighted. Then, based on the proposed literature review, a presentation about DDD opportunities and challenges in early product development was held. The goal of this part was to share the context of the research with the participants.

In the second part, the workshop aimed at knowledge sharing and then, in the third part, at speculating on the future DDD challenges. For both second and third parts of the workshop, the participants were invited to join an interactive online whiteboard on Klaxoon website. At the same time, they were required to join a voice channel so they could communicate with each other.

After a quick presentation of themselves, the participants addressed the series of questions detailed on figure 2. The questions were discussed one by one from Q1 to Q5 in the same way. First of all, participants proposed several answers to the current question through virtual post-it on the interactive whiteboard. Next, a discussion phase took place. Participants were invited to share, detail and discuss their answers with others. Participants' answers can be found on Figure 3, the colours of the different notes correspond to the different questions addressed. Question Q6 was an open debate in which participants agreed together on a ranking of DDD challenges. The ranking can be found on Figure 4.

10 participants actively took part in the proposed workshop, among them $4 \mathrm{PhD}$ students, 3 university professors, 2 research associates and 1 data analyst. Each participant reported an expertise in either product design, product-service system or data science. The individual point of view of each participant (background, profession, expertise, etc.) was hopefully source of diversity in the proposed answers.

The workshop generated an Idea Board (Figure 3) and a ranking of DDD challenges (Figure 4). In addition, the discussion phase of each question was transcribed anonymously. The authors have analysed and discussed these data in order to convey as accurately as possible the relevant contributions of the participants in this section.

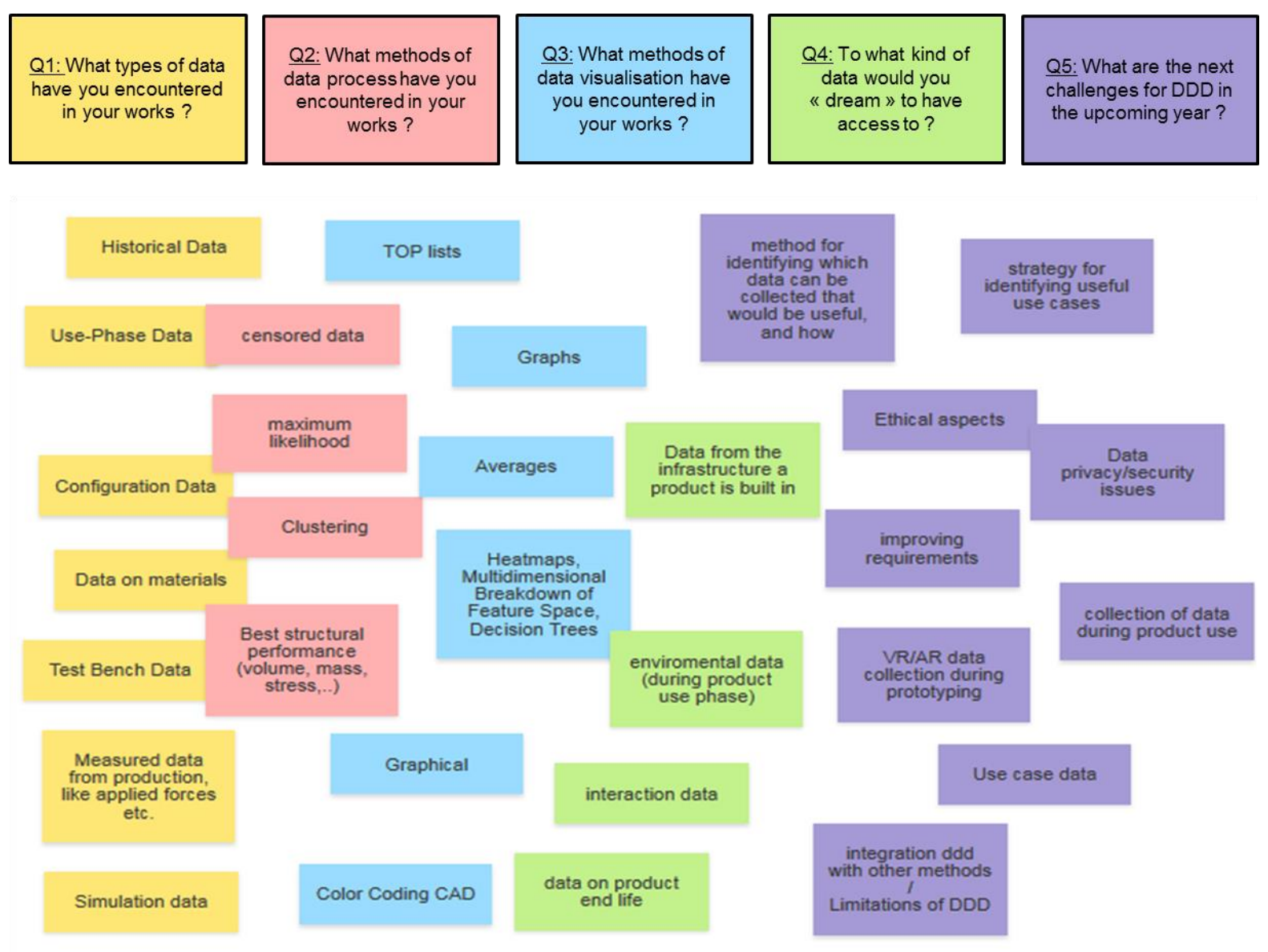

Figure 3. Workshop Idea Board 


\subsection{The knowledge sharing phase}

During this first part of the questions, participants were asked to share their knowledge about the type of data they use in their work (Q1). A wide range of data type was mentioned in accordance with the specialities of each participant, for example historical data, simulation data, test bench data, use-phase data, material data, etc. The questions of data processing (Q2) and data visualisation (Q3) were then addressed. Like the data types, the data processing methods were linked to the different participants' specialities. However, most participants used the same visualization tools in their works (graphics, heatmaps, top lists, etc.)

\subsection{The challenge identification phase}

After this knowledge sharing phase, a speculation phase was conducted with the direct aim of answering the workshop research question. Thus, the participants were first asked to think up their "dream" data (Q4), i.e. the data they find the most interesting to integrate in DDD approach. Then they were asked to state the future DDD challenges and to rank those challenges according to their importance (Q5 and Q6).

One main idea is found through the propositions of the participants for their "dream" data. Indeed, through the notes: "environmental data", "interaction data", "data on product end life" and "data from product's infrastructure", a common need for a product that can monitor both the user-product and the product-environment interactions is expressed (Figure 4). If such a product could have seemed utopic years ago, the growing accessibility and connectivity of sensors allow designers to draw closer to this product (Isaksson and Eckert 2020). However, monitoring every single parameter is also counterproductive and unrealistic. So, designers need to wisely think ahead what interaction to measure and how to measure it. This issue was underlying many of the proposed DDD challenges during the workshop.

The challenges suggested by the participants helped in giving a first draw of what the priority in DDD research could be. The propositions have been ranked on a priority scale from short term to long term (Figure 4). The participants' notes convey 4 main challenge ideas for DDD in early product development.

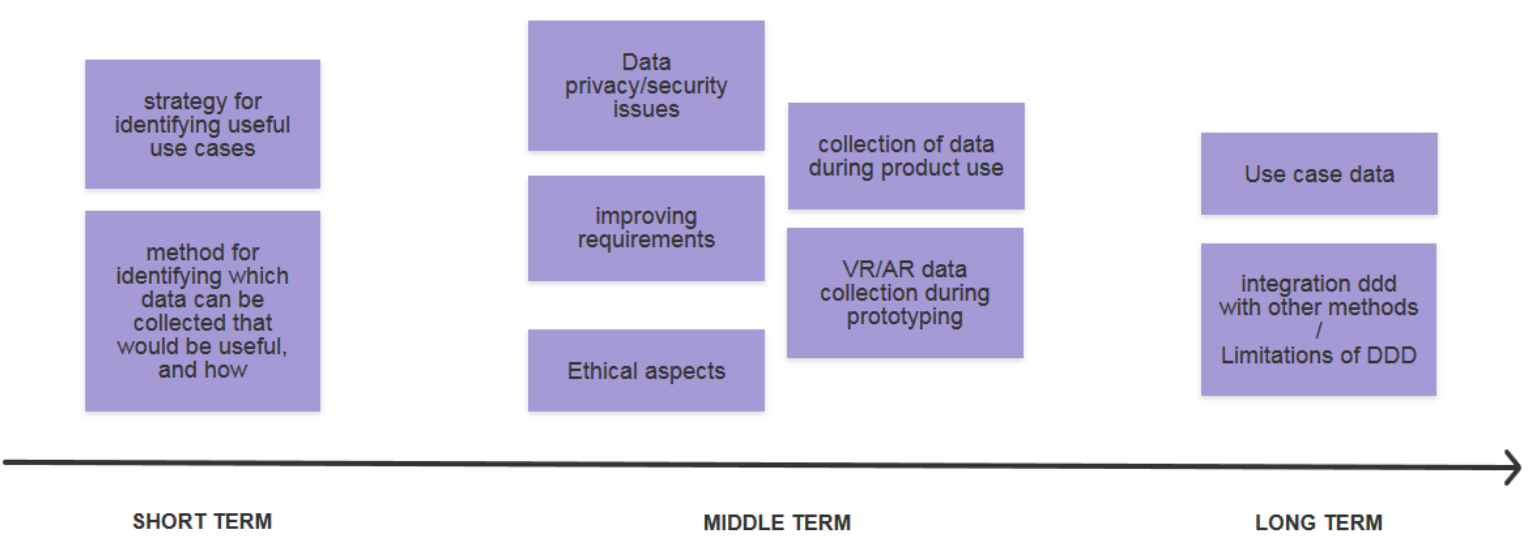

Figure 4. Ranking of the DDD challenges notes

The first research challenge idea that the participants chose unanimously for short term is expressed through the propositions: "method identifying which data can be collected that would be useful and how" and "strategy for identifying useful use cases". Both directly address a lack of research in DDD for early product design. Due to the recent democratisation of products connectivity, research is still in its infancy (Yu and Zhu 2016). DDD is missing robust and dedicated methodologies/frameworks. During the discussion phase, the participants raised numerous questions that the future DDD methods/frameworks should address: depending on the product type, which data should be collected? What are the collecting strategies? What is the minimum granularity of the data to collect? How can the value of data be judged?

Then, ranked middle term on the priority scale by the workshop participants were two different research challenges ideas. The notes "ethical aspects" and "data-privacy/security issues" address the contemporary need for protection of the users' data. Discussions among the participants concerned: 
the difficulty of making the most out of data while not infringing on privacy, the need for a code of conduct while designing with data and the specificities of business to business activities compared to business to consumer ones regarding data ethics. The other challenge idea raised in middle term is of a more technical nature. It concerns the means of capturing interaction data (with the user and with the environment) to be used during the prototyping and use phases. During the discussion phase, the main question was the choice of the most appropriate sensor for the data to be measured. Addressing this interrogation, the idea of a "DDD tools library" was suggested. A solution that could propose accordingly to the designers' needs data collection technics, the associated sensors, the pros and cons, etc. In that regard, the reference catalogue of Wilberg et al. (2018) was also mentioned.

The last research challenge idea ranked for long term is clearly expressed on the note "integration DDD with other methods / Limitations of DDD".

\section{DISCUSSION}

Through a synthesis of the results from both the literature review and the workshop, several challenges for DDD in the early stages of product development have been highlighted and ranked based on their priority (Figure 5). It is important to note that these proposed challenges are not mutually exclusive, as they may be interlinked on certain points.

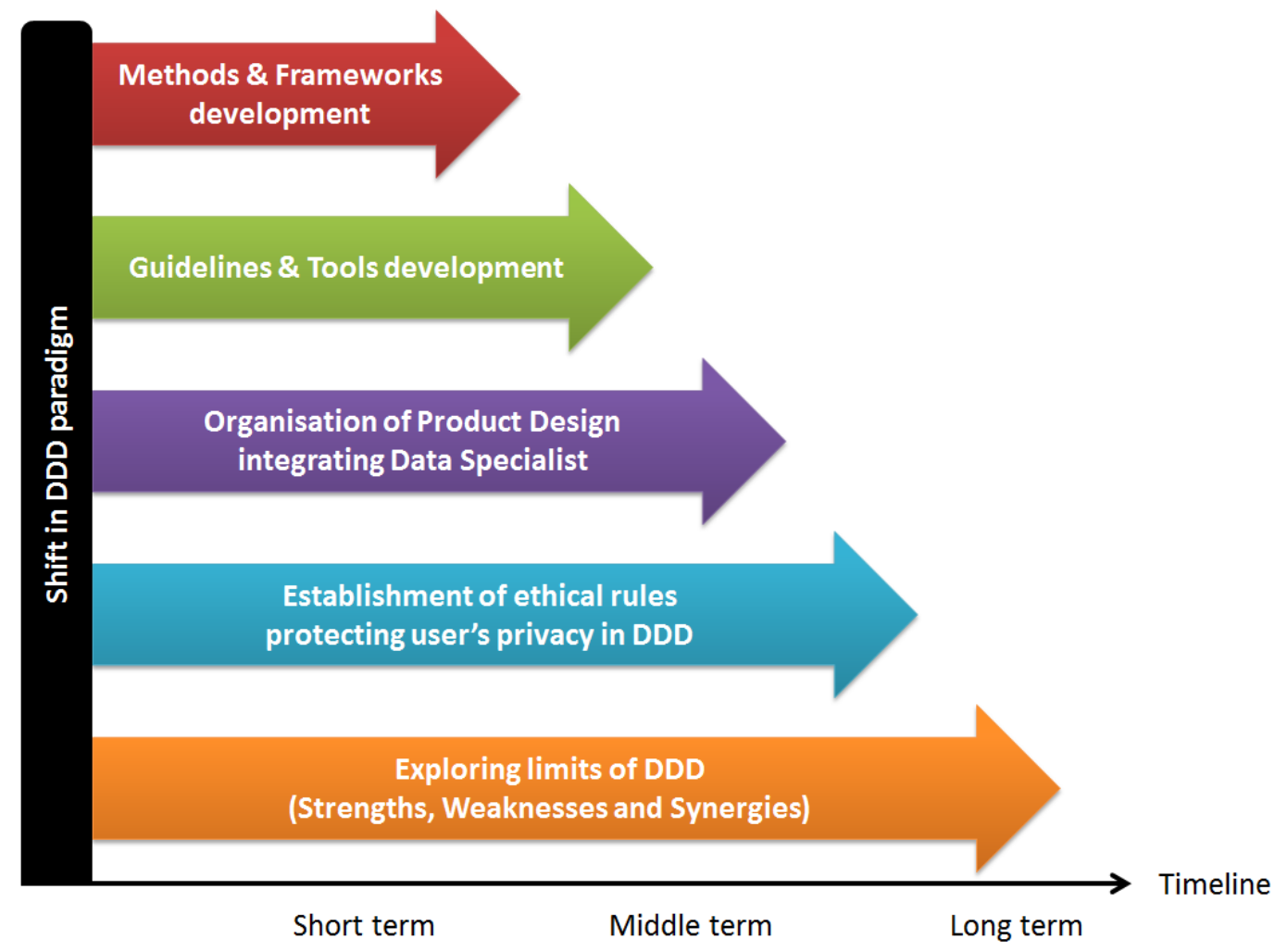

Figure 5. Proposition of a research agenda

Firstly, there is an important observation that could already be drawn out of the knowledge sharing phase: the fact that most of the data types proposed by the participants are not dedicated to a DDD approach. Meaning they would have been produced anyway even with other product development approaches (Bertoni 2020). Indeed, designers often compose with already existing data sets or easy to implement data collection. Thus, the first major challenge for DDD in the product development process is to shift paradigm. The collection and use of data should be considered at the forefront of the early design process instead of being a subsidiary tool (Cantamessa et al. 2020). In order to progress toward this shift, research need to develop new frameworks and methods for DDD. The majority of participants identified this need as a challenge for short term. Indeed, anticipating the collection and use of data during early product design would enable the development of new types of smart connected products. With the feedback of relevant data, these products will be customizable, flexible and even remotely upgradable (Isaksson and Eckert 2020). For example, in the automotive industry, 
Tesla cars seem to be pioneers of this kind of product as they are more open-ended and readily changeable. Via software upgrades, performances, on-board system and functionalities can be improved (Lyyra and Koskinen 2016). Designers could first experiment DDD approaches and embrace the forecasted potential of data in early product development through use cases. A highlight of their potential may also contribute to the paradigm shift.

Secondly, another meaningful observation from the knowledge sharing phase is that the visualisation tools used by the participants are common but not specific to data-science. It could be interesting to measure the impact of using advanced data visualization tools when a DDD approach is conducted. Indeed, participants have identified as a middle term challenge the need to develop a set of DDD guidelines and tools. These should complement the future methods/framework mentioned earlier. As DDD is a recent approach in product development, there is a need for guidelines to assist designers towards the most appropriate solutions. Likewise, this new approach also brings new opportunities for tools to improve the quality, time and costs of the design process. In addition, both guidelines and tools should introduce data collection and use from the early stages of product design. As a result, designers will be able to better anticipate the design of the next generation products and provide effective solutions for the maintenance or improvement of products during the use phase. As mentioned during the workshop, tools could for example provide designers with guidance on which sensors to use for which data.

Thirdly, to go further, research on DDD integrating data specialists (i.e. data scientist or data analyst) could also be fruitful. There is an opportunity to include their specific skills, methods and tools into the product development process (Bstieler et al. 2018). Indeed, only one of the workshop participants was a data specialist, the others assumed this role occasionally in their work but may lack some knowledge related to this field. In this regard, and with the rapid development of technologies, designers may also miss out on more suitable solutions for their products. Integrating these new professions to support the upstream design phases is a middle term challenge. It is necessary to organise an efficient workflow between the different stakeholders as well as an effective communication to minimise bias on data expectations and/or interpretations. Indeed, in the early stages of product design, the designers must help the data specialists to grasp the potential of the product in terms of data. The data specialists will then propose relevant capture solutions that maximise this potential. Afterwards, during the use phase, the data specialists must analyse and structure the data so that the designers can interpret it and translate it into useful product design information.

Next, although this is not exclusively a problem of design science, it appeared important for the participants to regulate the collection and use of data in the future of DDD. The ethical aspects are already ambiguous on the internet; the increasing connectivity brings the question also on physical products. The collection and usage of interaction data between a physical product, its environment and its user should respect the privacy of the latter. A challenge for the future of DDD is the establishment of ethical rules protecting user's privacy. As an inspiration, the recent general data protection regulations on internet may be considered.

At last, for the workshop participants, it seemed interesting to explore the limits of the DDD approach and highlight its strengths and weaknesses. DDD is still in its infancy, but like all design approach it has its strength and flaws. After finding them out, future research could for example integrate DDD with other design methods/tools to explore synergies and overcome possible limitations. This challenge implies a more mature approach of DDD so it is ranked for long term.

\section{CONCLUSION}

This paper objective was to propose few leads for the future research on DDD in the early stages of the product development process. To do so, the paper first highlights some DDD examples and establishes a review of the literature on DDD challenges. Then, on the basis of this preliminary study, a workshop is conducted. After getting acquainted with the subject and its stakes, the different participants were able to propose answers to the research question. The identified challenges in both the literature review and the workshop are then discussed and synthesised in a concise list of research leads. This paper also ranks the priority of those leads on a temporal scale. The primary priority identified is to change the paradigm regarding the use of data in the upstream phases of product design. Once this lock is lifted, research should naturally move forward. Frameworks, methods, tools and guidelines for 
DDD in the early stages of product development could be proposed to embrace the newly given opportunities. In addition, the integration of data specialist as new stakeholders of product design could be organised and a set of ethical rules protecting user's data could also be proposed. For future works, further investigations in the identified research leads could be made in order to grasp all the issues at stakes. Moreover, solutions answering the identified challenges needs may be proposed. These new advances in research could then be tested with case studies in the product design field. Their relevance in comparison to the existing solutions should then be measured in order to justify the implementation of the data. Thus, their potential could be highlighted to contribute to the paradigm shift.

\section{ACKNOWLEDGEMENTS}

The authors would like to warmly thank the active participants of our DESIGN 2020 workshop. The current world situation forces us to limit our movements and meet virtually. It is obviously a hindrance to communication, exchange and creativity during workshops. However, despite these conditions, some interesting discussions took place. In our opinions, the identified research leads seem promising and their further investigations should hopefully help design science to move forward.

\section{REFERENCES}

Bae, J.K., Kim, J., 2011. Product development with data mining techniques: A case on design of digital camera. Expert Systems with Applications 38, 9274-9280. https://doi.org/10.1016/j.eswa.2011.01.030

Bertoni, A., 2020. Data-Driven Design in concept development: systematic review and missed opportunities. Proceedings of the Design Society: DESIGN Conference 1, 101-110. https://doi.org/10.1017/dsd.2020.4

Bertoni, A., 2018. Role and Challenges of Data-Driven Design in the Product Innovation Process. IFACPapersOnLine 51, 1107-1112. https://doi.org/10.1016/j.ifacol.2018.08.455

Bstieler, L., Gruen, T., Akdeniz, B., Brick, D., Du, S., Guo, L., Khanlari, M., McIllroy, J., O’Hern, M., Yalcinkaya, G., 2018. Emerging Research Themes in Innovation and New Product Development: Insights from the 2017 PDMA-UNH Doctoral Consortium. Journal of Product Innovation Management 35, 300307. https://doi.org/10.1111/jpim.12447

Cantamessa, M., Montagna, F., Altavilla, S., Casagrande-Seretti, A., 2020. Data-driven design: the new challenges of digitalization on product design and development. Design Science 6. https://doi.org/10.1017/dsj.2020.25

Chen, L., Wang, P., Dong, H., Shi, F., Han, J., Guo, Y., Childs, P.R.N., Xiao, J., Wu, C., 2019. An artificial intelligence based data-driven approach for design ideation. Journal of Visual Communication and Image Representation 61, 10-22. https://doi.org/10.1016/j.jvcir.2019.02.009

Chien, C.-F., Kerh, R., Lin, K.-Y., Yu, A.P.-I., 2016. Data-driven innovation to capture user-experience product design: An empirical study for notebook visual aesthetics design. Computers \& Industrial Engineering 99, 162-173. https://doi.org/10.1016/j.cie.2016.07.006

Chiu, M.-C., Lin, K.-Z., 2018. Utilizing text mining and Kansei Engineering to support data-driven design automation at conceptual design stage. Advanced Engineering Informatics 38, 826-839. https://doi.org/10.1016/j.aei.2018.11.002

Chowdhery, A.S., Bertoni, M., Wall, J., Larsson, T., n.d. A data-driven design framework for early stage PSS design exploration 16.

Faste R., Roth B. and Wilde D.J., 1993. Integrating Creativity into the Mechanical Engineering Curriculum, ASME Resource Guide to Innovation in Engineering Design, American Society of Mechanical Engineers.

Ghosh, D., Olewnik, A., Lewis, K., Kim, J., Lakshmanan, A., 2017. Cyber-Empathic Design: A Data-Driven Framework for Product Design. Journal of Mechanical Design 139. https://doi.org/10.1115/1.4036780

Gorkovenko, K., Burnett, D.J., Thorp, J.K., Richards, D., Murray-Rust, D., 2020. Exploring The Future of DataDriven Product Design, in: Proceedings of the 2020 CHI Conference on Human Factors in Computing Systems. Presented at the CHI '20: CHI Conference on Human Factors in Computing Systems, ACM, Honolulu HI USA, pp. 1-14. https://doi.org/10.1145/3313831.3376560

Isaksson, O., Eckert, C., 2020. Product Development 2040. The Design Society. https://doi.org/10.35199/report.pd2040

Kim, H. H. M., Liu, Y., Wang, C. C., and Wang, Y., 2017. Special Issue: Data-Driven Design (D3), Journal of Mechanical Design 139, 11. https://doi.org/10.1115/1.4037943

Klein, P., van der Vegte, W.F., Hribernik, K., Klaus-Dieter, T., 2019. Towards an Approach Integrating Various Levels of Data Analytics to Exploit Product-Usage Information in Product Development. Proceedings of the Design Society: International Conference on Engineering Design 1, 2627-2636.

https://doi.org/10.1017/dsi.2019.269 
Kusiak, A., 2009. Innovation: A data-driven approach. International Journal of Production Economics 122, 440448. https://doi.org/10.1016/j.ijpe.2009.06.025

Kwon, H., Park, Y., Geum, Y., 2018. Toward data-driven idea generation: Application of Wikipedia to morphological analysis. Technological Forecasting and Social Change 132, 56-80. https://doi.org/10.1016/j.techfore.2018.01.009

Labrinidis, A., Jagadish, H.V., 2012. Challenges and opportunities with big data. Proceedings of the VLDB Endowment 5, 2032-2033. https://doi.org/10.14778/2367502.2367572

Lin, K.-Y., Chien, C.-F., Kerh, R., 2016. UNISON framework of data-driven innovation for extracting user experience of product design of wearable devices. Computers \& Industrial Engineering 99, 487-502. https://doi.org/10.1016/j.cie.2016.05.023

Lützenberger, J., Klein, P., Hribernik, K., Thoben, K.-D., 2016. Improving Product-Service Systems by Exploiting Information From The Usage Phase. A Case Study. Procedia CIRP 47, 376-381. https://doi.org/10.1016/j.procir.2016.03.064

Lyyra, A.K., Koskinen, K.M., 2016. The Ambivalent Characteristics of Connected, Digitised Products: Case Tesla Model S, in: Lundh Snis, U. (Ed.), Nordic Contributions in IS Research, Lecture Notes in Business Information Processing. Springer International Publishing, Cham, pp. 57-69. https://doi.org/10.1007/978-3319-43597-8_5

Ma, H., Chu, X., Lyu, G., Xue, D., 2017. An Integrated Approach for Design Improvement Based on Analysis of Time-Dependent Product Usage Data. Journal of Mechanical Design 139. https://doi.org/10.1115/1.4037246

Pahl, G., Beitz, W., 1996. A Systematic Approach. Engineering Design https://doi.org/10.1007/978-1-4471-3581-4

Ranscombe, C., Kinsella, P., Blijlevens, J., 2017. Data-Driven Styling: Augmenting Intuition in the Product Design Process Using Holistic Styling Analysis. Journal of Mechanical Design 139. https://doi.org/10.1115/1.4037249

Romelfanger, M., Kolich, M., 2019. Comfortable automotive seat design and big data analytics: A study in thigh support. Applied Ergonomics 75, 257-262. https://doi.org/10.1016/j.apergo.2018.08.020

Shin, J.-H., Kiritsis, D., Xirouchakis, P., 2015. Design modification supporting method based on product usage data in closed-loop PLM. International Journal of Computer Integrated Manufacturing 28, 551-568. https://doi.org/10.1080/0951192X.2014.900866

van der Vegte, W.F., Kurt, F., Şengöz, O.K., 2019. Simulations Based on Product-Usage Information From Connected Products to Support Redesign for Improved Performance: Exploration of Practical Application to Domestic Fridge-Freezers. Journal of Computing and Information Science in Engineering 19. https://doi.org/10.1115/1.4042537

Wilberg, J., Lau, K., Nützel, T., Hollauer, C., Omer, M., 2018. Development of a catalogue supporting idea generation for internet of things use cases. Presented at the 15th International Design Conference, pp. 14531464. https://doi.org/10.21278/idc.2018.0215

Yang, B., Liu, Y., Liang, Y., Tang, M., 2019. Exploiting user experience from online customer reviews for product design. International Journal of Information Management 46, 173-186. https://doi.org/10.1016/j.ijinfomgt.2018.12.006

$\mathrm{Yu}, \mathrm{C}$., Zhu, L., 2016. Product design pattern based on big data-driven scenario. Advances in Mechanical Engineering 8, 168781401665680. https://doi.org/10.1177/1687814016656805

Zheng, P., Xu, X., Chen, C.-H., 2020. A data-driven cyber-physical approach for personalised smart, connected product co-development in a cloud-based environment. Journal of Intelligent Manufacturing 31, 3-18. https://doi.org/10.1007/s10845-018-1430-y 